http://jmscr.igmpublication.org/home/ ISSN (e)-2347-176x ISSN (p) 2455-0450 crossref DOI: https://dx.doi.org/10.18535/jmscr/v8i1.89

\title{
Cells in pleural fluid and their value in differential diagnosis
}

\author{
Authors \\ Dr Mohammed Abdul Sameer ${ }^{1}$, Dr Priyanka Rameshchandra Chandak², \\ Dr Umme Ammarah Farooqui ${ }^{3}$ \\ ${ }^{1}$ Professor \& Head, ${ }^{2}$ Senior Resident, ${ }^{3}$ Junior Resident
}

Department of Pathology, of Dr. Shankarrao Chavan Government Medical College, Nanded,

Maharashtra, India

\begin{abstract}
Background: Both non-malignant and malignant causes of effusion can be identified by relatively noninvasive technique of pleural fluid cytology. With this basis the present study on cytology of pleural fluids was taken up. The cytological study of body effusions is a complete diagnostic modality which aims at pointing out the etiology of effusion as well as in certain cases a means of prognostication of the disease process.
\end{abstract}

Materials and Methods: Sixty samples of pleural fluid were examined for total cell count, cell type and cellular features and AFB staining. They were also subjected to biochemical study to fluids out the level of protein and glucose and ADA level. .

Results: The medical records of all 60 patients with pleural effusion were available for review. The ages of the patients ranged from four years to 75 years, with maximum cases $(29.36 \%)$ in the sixth decade. Male preponderance of effusion was noted; the ratio of male to female being 1.2:1. Of all the effusions, 31.19\% were hemorrhagic; $26.61 \%$ turbid, $23.85 \%$ clear, $11.93 \%$ purulent, $3.67 \%$ viscous and $2.75 \%$ opalescent. Transudates comprised $18 \%$ of cases. Most of them were secondary to cirrhosis and congestive cardiac failure.

Overall $82 \%$ of pleural effusions were exudative in nature. The most frequent cause of exudative effusion was tuberculosis (39.02\%) followed by malignancy (30.49\%), paramalignancy (8.54\%), pneumonia (7.32\%), and empyema (4.89\%).

Conclusions: The most useful test in establishing the diagnosis of pleural effusion is pleural fluid cytology and pleural fluid cell count. Cytologic study of pleural fluid is a complete diagnostic modality which aims at pointing out the etiology of effusion as well as, in certain cases, a means of prognostication of disease process.

Keywords: Effusion; pleural fluid; malignant effusion.

\section{Introduction}

Patients with an undiagnosed pleural effusion should be evaluated in an individualised stepwise manner. The initial two steps should be relatively non-invasive and include clinical evaluation and cytologic study.
Aspiration of serous cavities is a simple and relatively noninvasive technique to achieve a diagnosis. The information provided by body fluid analysis serves several functions, first, it assists the clinician in formulating, in order of priority, a list of differential diagnoses, second it allows one to follow the result of therapy. ${ }^{[1]}$ 
The pleural space is a potential space between the visceral and parietal layers of the pleurae that normally confined to lung. Both non-malignant and malignant causes of effusion can be identified by the relatively non-invasive technique of pleural fluid cytology. With this basis the present study on cytology of pleural fluids was taken as 0.1-0.2 $\mathrm{mL} / \mathrm{kg}$ body weight of fluid. ${ }^{[2]}$ Pleural effusion is an abnormal accumulation of fluid in the pleural cavity and remains the most common manifestation of pleural pathology. ${ }^{[2]}$ Although, a variety of clinical conditions such as heart failure, malignancy, pneumonia, tuberculosis may be the cause of a pleural effusion, the possibility of a malignant involvement of pleural cavity should always be considered in difficult-to-diagnose cases. Because percutaneous access of the pleural space is relatively simple, techniques such as pleural biopsy and thoracoscopy have become very popular. However, such facilities are available only in advanced pulmonary medicine centers, pleural fluid analysis and cytology remain the mainstay for diagnosing the various pulmonary diseases. ${ }^{[3]}$

Levels of adenosine deaminase (ADA) and AFB staining are particularly useful in areas where the prevalence of tuberculosis is high. ADA is an enzyme involved in purine metabolism. It is needed for the breakdown of nucleic acids in tissues. ADA value above $40 \mathrm{IU} / \mathrm{L}$ are known to well correlate with tubercular pathology in various studies and help to differentiate between tubercular and nontubercular exudative pleural effusion. ${ }^{[12,13]}$

Thus cytological study of body effusions is a complete diagnostic modality which aims at pointing out the etiology of effusion as well as in certain cases a means of prognostication of the disease process. The diagnostic performance of the cytologic study of the fluid may be attributable to the fact that the cell population present in sediment is representative of a much larger surface area than that obtained by needle biopsy. ${ }^{[4,5]}$

\section{Materials and Methods}

This study on pleural fluid cytology was undertaken in the Department of Pathology, of Dr. Shankarrao Chavan Government Medical College, Nanded, over a period of 1 year study. Relevant and available clinical information regarding age, sex, symptoms and accompanying signs was obtained from the patients.

An effort was made in this study to process the pleural fluid specimens as expeditiously as possible, the majority were processed immediately. But in a small number, when there was a delay, these specimens were stored in the refrigerator at $4^{\circ} \mathrm{C}$. The fluid was divided into two parts, one part was used for cell count and the other part was poured into the centrifuge tubes and centrifuged for 10 minutes at $2000 \mathrm{rpm}$. The supernatant was poured off. Part of the sediment was transferred to a clean glass slide and mixed with a part of $1 \%$ toluidine blue. After placing the cover slip, the slide was observed under the microscope for immediate identification of cell morphology.

\section{Results}

The medical records of all 60 patients with pleural effusion were available for review. The ages of the patients ranged from four years to 75 years, with maximum cases $(29.36 \%)$ in the sixth decade. Male preponderance of effusion was noted; the ratio of male to female being 1.2:1. Of all the effusions, $31.19 \%$ were hemorrhagic; $26.61 \%$ turbid, $23.85 \%$ clear, $11.93 \%$ purulent, $3.67 \%$ viscous and $2.75 \%$ opalescent. Transudates comprised $18 \%$ of cases. Most of them were secondary to cirrhosis and congestive cardiac failure [Table 1].

Overall $82 \%$ of pleural effusions were exudative in nature. The most frequent cause of exudative effusion was tuberculosis $(39.02 \%)$ followed by malignancy $(30.49 \%)$, paramalignancy $(8.54 \%)$, pneumonia $(7.32 \%)$, and empyema $(4.89 \%)$. In $53.57 \%$ of malignant effusions there were predominantly lymphocytes. All samples of parapneumonic effusions had polymorphonuclear 
cells as the predominant cell type. Approximately $82 \%$ of effusions had protein level greater than 3 gm\%, hence were exudative [Table 2].

Most of the transudative effusions were clear in appearance and most of the exudative effusions were hemorrhagic.

Clinically 33 cases were diagnosed to be tuberculosis but with cytological and biochemical study only 26 cases were confirmed to be of tuberculosis which shows cob web formation. Approximately $96.88 \%$ of samples of tuberculous effusion had lymphocyte count greater than $50 \%$, $81.25 \%$ had protein level greater than $5 \mathrm{gm} \%$ and $90.63 \%$ had pleural fluid glucose greater than 60 $\mathrm{mg} / \mathrm{dl}$ [Table 3].

Out of them $89.29 \%$ samples were exudative and $10.71 \%$ were transudative. $71.43 \%$ of malignant effusions were hemorrhagic.
Diagnosis of metastatic adenocarcinoma was made in pleural fluid cytological examination of two cases. All the fluids showed sheets, clusters and acini of large tumor cells having large dense nuclei and pale cytoplasm. Around 55\% of patients were in the sixth decade. It was noted that 88.89\% were exudative effusions and all samples were hemorrhagic. Diagnosis of metastatic papillary carcinoma was made in 1 samples. Smears showed clusters and papillary groups of large abnormal epithelial cells having large dense nuclei and conspicuous nucleoli. Nuclear chromatin was coarse. A few psammoma bodies were seen. $50 \%$ of patients were in the sixth decade. All samples were exudative and hemorrhagic.

Table 1: Clinical causes of transudative and exudative pleural effusion, total and differential cell count and biochemical features

\begin{tabular}{|c|c|c|c|c|c|c|c|c|c|c|c|c|c|}
\hline \multirow[t]{2}{*}{$\begin{array}{l}\text { Causative } \\
\text { Factor }\end{array}$} & \multirow[b]{2}{*}{ 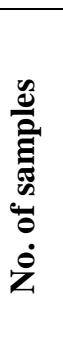 } & \multicolumn{3}{|c|}{ TLC cells/cu.mm } & \multicolumn{7}{|c|}{ Predominant cells } & \multicolumn{2}{|c|}{$\begin{array}{l}\text { Protein } \\
(\text { gm\%) }\end{array}$} \\
\hline & & :̊ำ & 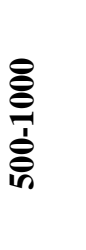 & 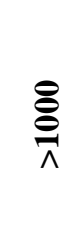 & $\begin{array}{l}\frac{\mathscr{L}}{2} \\
\frac{0}{0} \\
\frac{0}{0} \\
0\end{array}$ & 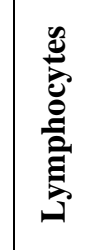 & & 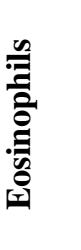 &  & & 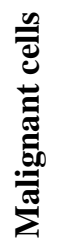 & $<3$ & $>\mathbf{3}$ \\
\hline $\begin{array}{l}\text { Chronic } \\
\text { inflammatory lesion }\end{array}$ & 33 & 1 & 12 & 20 & & 1 & 32 & - & - & - & & - & 33 \\
\hline Pneumonia & 6 & 2 & 4 & - & & 6 & - & - & - & - & & - & 6 \\
\hline Empyema & 4 & - & 1 & 3 & & 4 & - & - & - & - & & - & 4 \\
\hline Malignancy & 5 & 1 & 2 & 2 & & 1 & 1 & - & - & 3 & & 1 & 4 \\
\hline Cirrhosis & 6 & 2 & 4 & - & & 1 & 5 & - & - & - & & 1 & 5 \\
\hline $\begin{array}{l}\text { Congestive cardiac } \\
\text { Failure }\end{array}$ & 6 & 5 & 1 & - & & 1 & 5 & - & - & - & & 1 & 5 \\
\hline
\end{tabular}

Table No. 2 : Diagnostic Distribution of Pleural Fluid $(n=60)$

\begin{tabular}{|l|c|c|c|}
\hline Sr No. & Diagnosis & No. Of cases & Percentage \\
\hline 1 & Cirrhosis & 6 & $10 \%$ \\
\hline 2 & Congestive cardiac failure & 6 & $10 \%$ \\
\hline 3 & Malignancy & 5 & $8.33 \%$ \\
\hline 4 & Tuberculosis & 33 & $55 \%$ \\
\hline 5 & Pneumonia & 6 & $10 \%$ \\
\hline 6 & Empyema & 4 & $6.66 \%$ \\
\hline
\end{tabular}




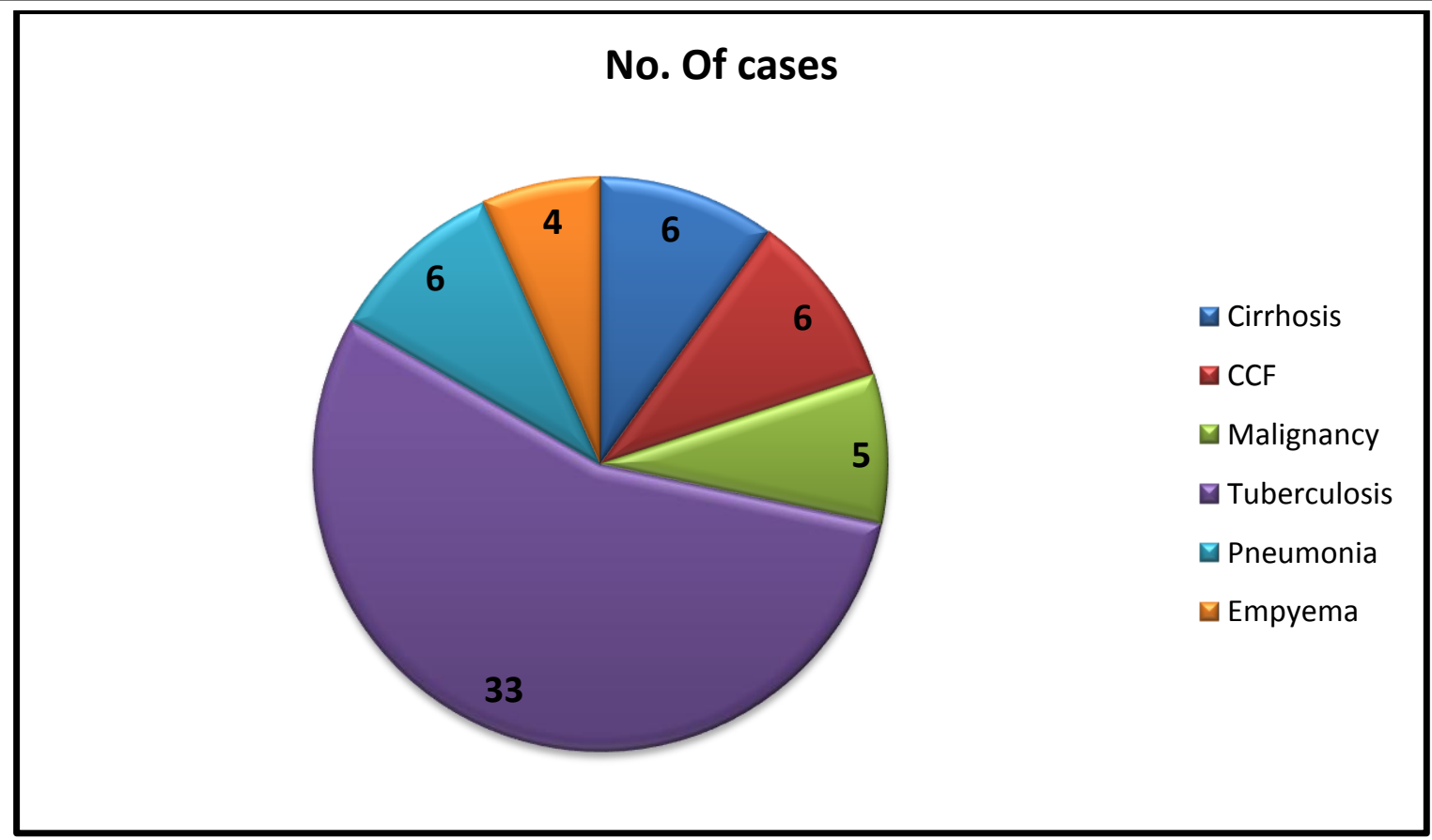

\section{Graphical representation showing diagnostic distribution of pleural fluids}

Table No. 3: Chronic Inflammatory Effusion Lymphocyte Countand Biochemical Values

\begin{tabular}{|c|c|c|c|}
\hline NO. Of samples & Lymphocyte count (\%) & Protein (mg \%) & Glucose (mg \%) \\
\hline & $<\mathbf{5 0}$ & 3-5 & $>60$ \\
\hline 33 & 30 & 28 & 13 \\
\hline
\end{tabular}

Table No 4: Role of Cytology to Establish Definative Diagnosis

\begin{tabular}{|l|c|c|c|c|}
\hline $\begin{array}{l}\text { Initial } \\
\text { Clinical } \\
\text { diagnosis }\end{array}$ & $\begin{array}{c}\text { No. Of } \\
\text { samples }\end{array}$ & Cytological diagnosis & $\begin{array}{c}\text { No. Of } \\
\text { samples }\end{array}$ & Percentage \\
\hline $\begin{array}{l}\text { Chronic } \\
\text { inflammatory } \\
\text { lesion }\end{array}$ & 33 & Chronic inflammatory lesion & 26 & $78.78 \%$ \\
& & Metastatic adenocarinoma & 2 & $6.06 \%$ \\
& & Mesothelioma & 2 & $6.06 \%$ \\
\hline Malignancy & 5 & Metastatic papillary carcinoma & 1 & $3 \%$ \\
\hline Pneumonia & 6 & Non Hodgkin lymphoma & 2 & $6.06 \%$ \\
\hline Cirrhosis & 6 & Malignant effusions & 5 & $100 \%$ \\
\hline & & Pneumonia & 5 & $83.3 \%$ \\
\hline $\begin{array}{l}\text { Congestive } \\
\text { cardiac failure }\end{array}$ & 6 & Cirrhosis & 4 & $66.6 \%$ \\
\hline Empyema & 4 & Inflammatory smear & 2 & $33.3 \%$ \\
\hline
\end{tabular}




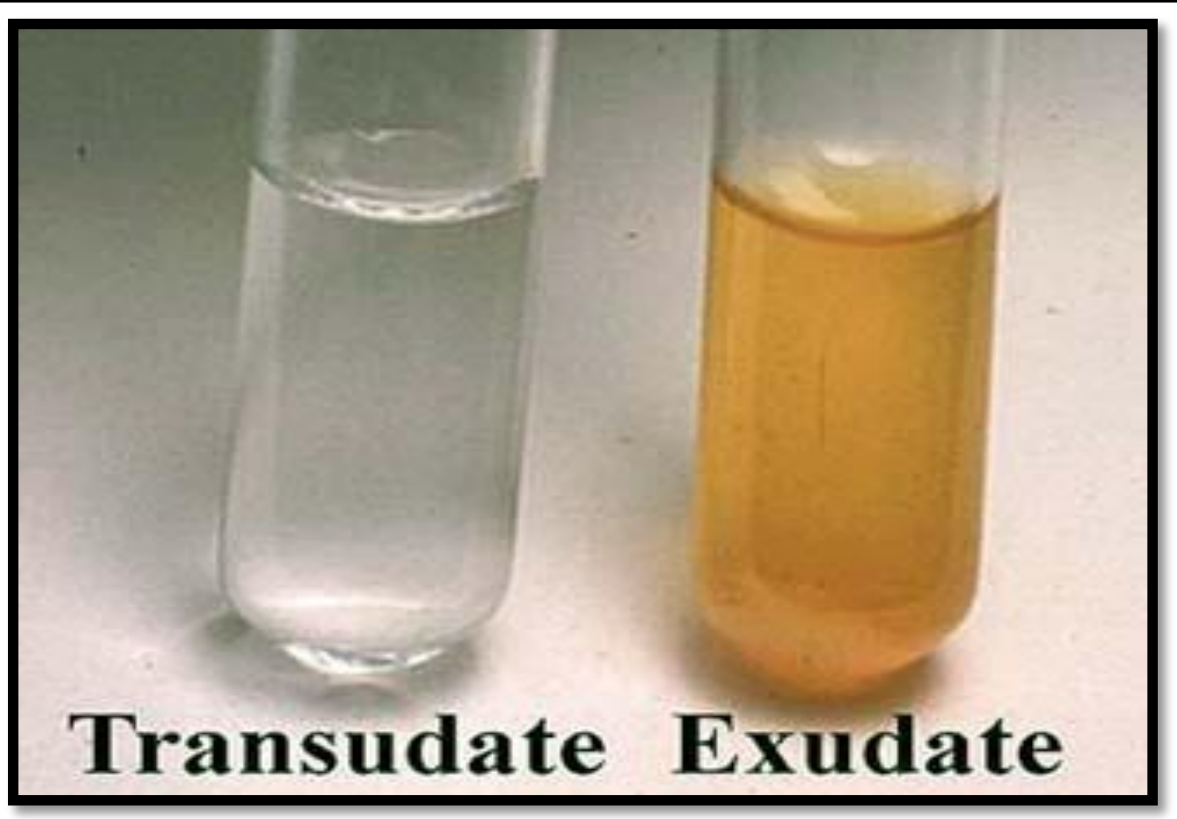

Fig 1: Gross showing colour of transudative and exudative fluids

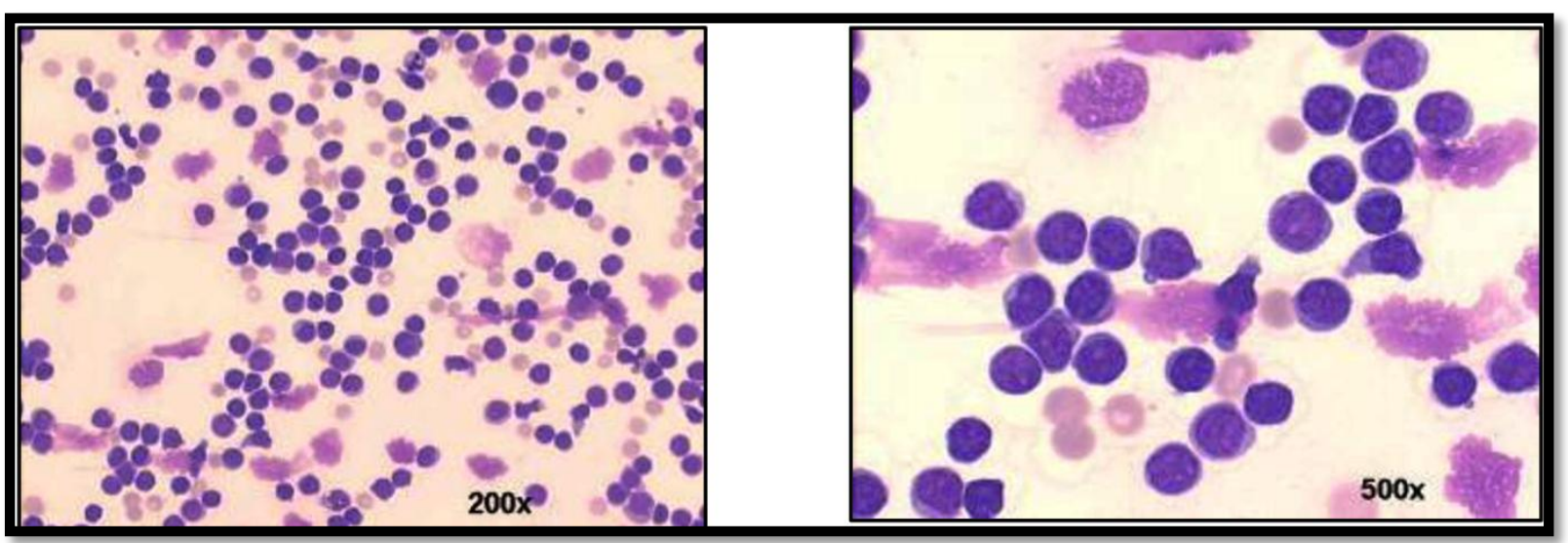

Fig 2: Tuberculous Pleural Effusion: Smear showing increased lymphocyte count in a case of tuberculous pleural effusion. (High power: 200X \& 500X, MGG STAIN)

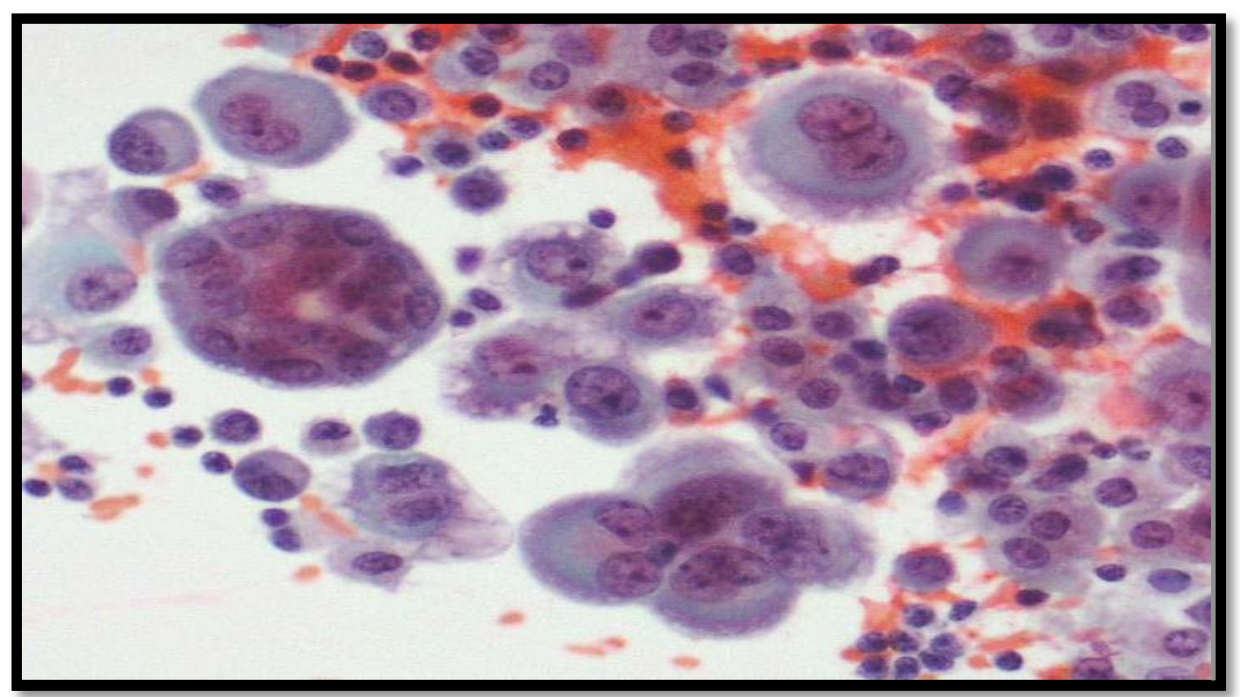

Fig no: 3 Mesothelioma: Highly cellular smear study single enlarged cells/ in sheets, 3-D groups with scalloped contours, sometimes papillary with stromal core wide intercellular windows, central enlarged nuclei, multinucleated cells with prominent nucleoli. (High power: 40X) 


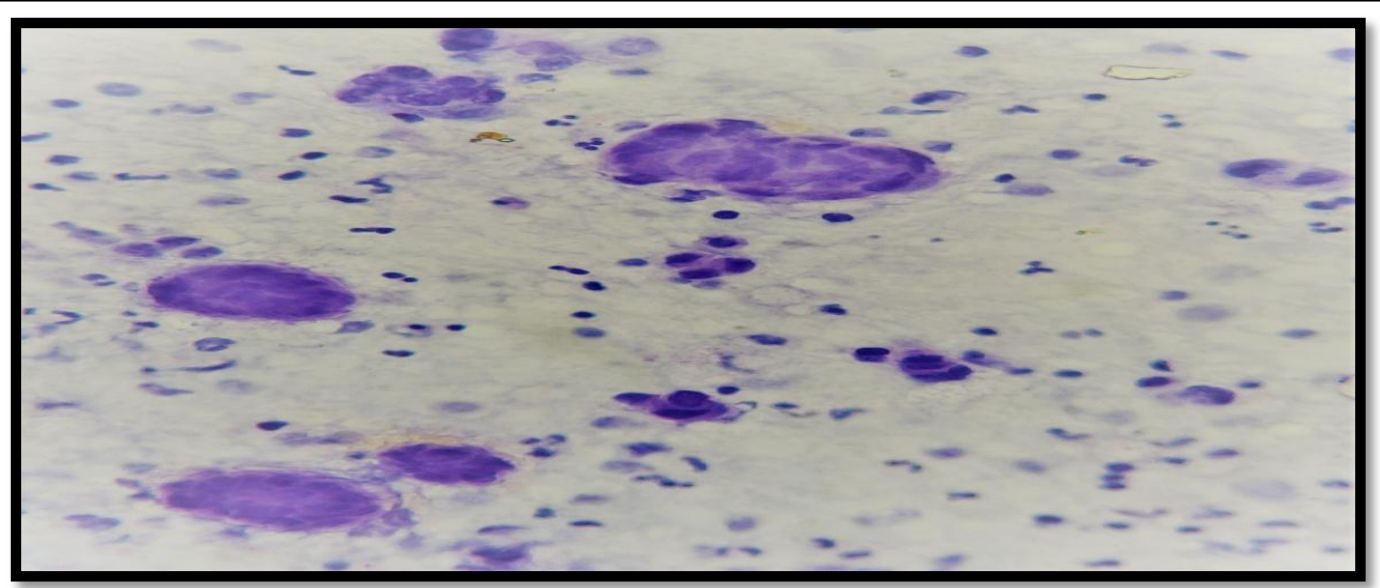

Fig 4: Positive For Malignancy S/O Adenocarcinoma: Highly cellular smear study shows malignant cells with hyperchromatic, pleomorphic nuclei and scanty cytoplasm arranged in 3-D clusters and balls, in a case of pleural effusion. (High power: 40X)

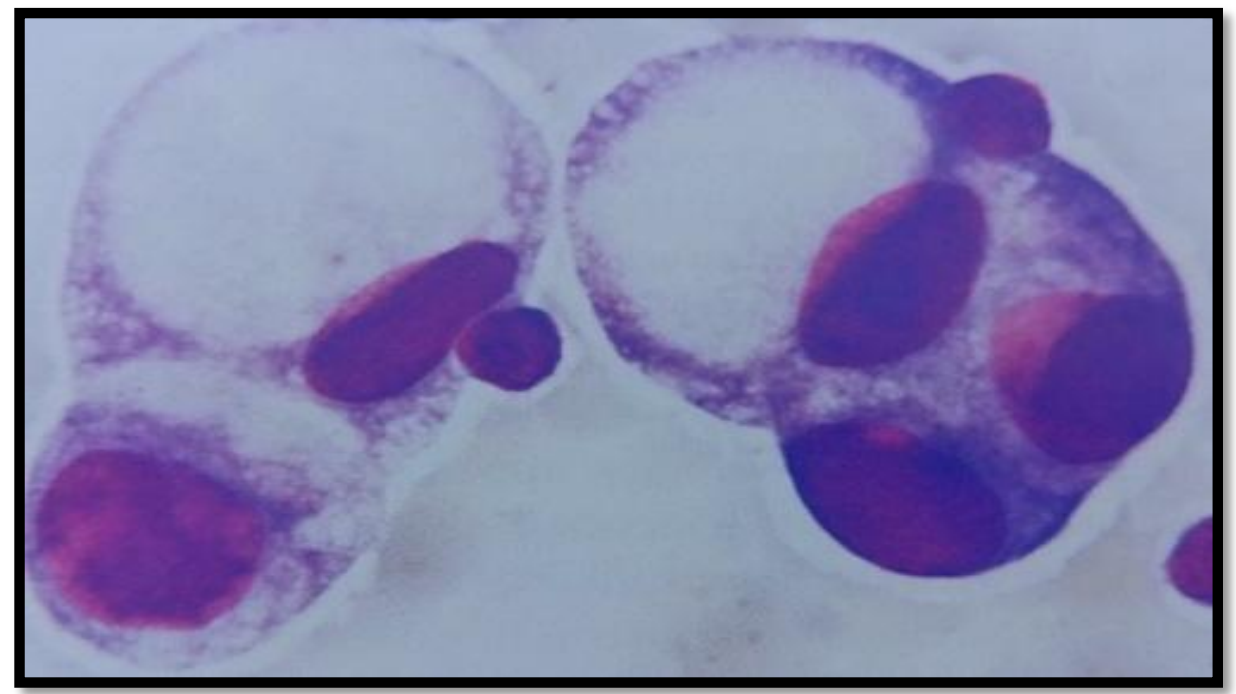

Fig 5: Pleural fluid .Adenocarcinoma, lung primary. Vacuolated cells are often present in serous effusions. In this case, the adenocarcinoma cells contain mucin but similar appearances can be seen in mesothelial cells. A mucin stain is mandatory in such cases. (MGG X Ol)

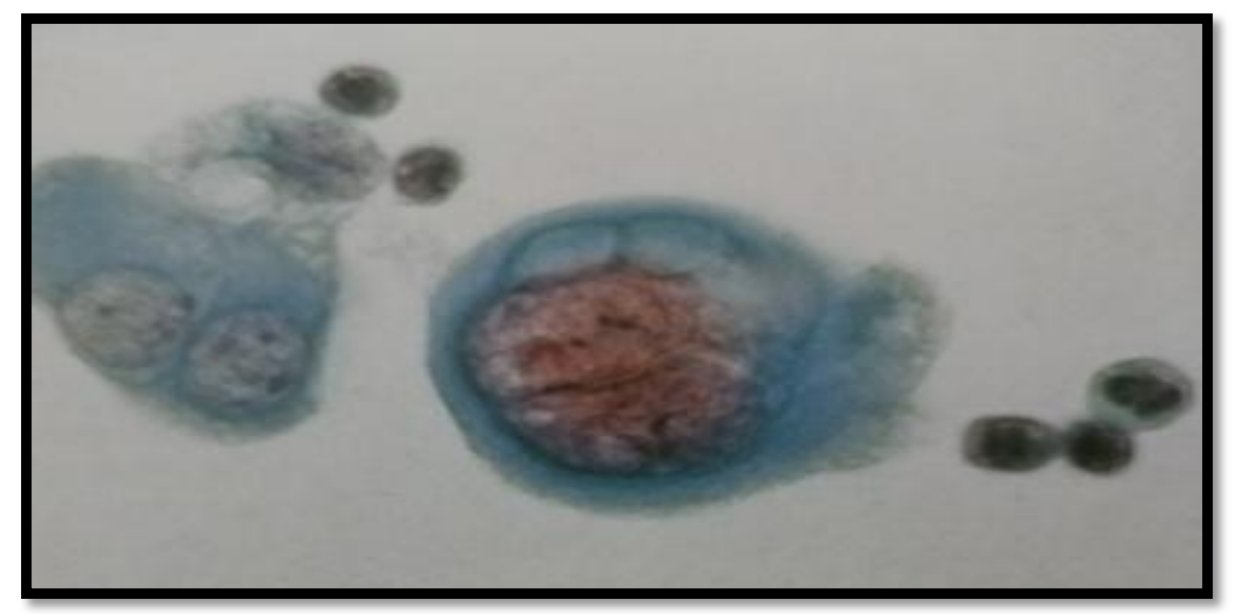

Fig 6: Pleural fluid. Squamous cell carcinoma, lung primary. Metastatic squamous cell carcinoma may be difficult to distinguish from adenocarcinoma if keratinization is scanty. Degenerative nuclear vacuolation may simulate intracellularmucin. (Papanicolaou X HP) 


\section{Discussion}

The relative ease of pleural fluid aspiration, analysis and cytological examination has kept alive the search for a test to unequivocally differentiate the various causes of effusion. The cytological examination of body effusion is a complete diagnostic modality which aims at pointing out the etiology of effusions. The diagnostic performance of the cytologic study of the fluid may be attributable to the fact that the cell population present is representative of a much larger surface area than that obtained by needle biopsy. ${ }^{[6]}$

One study showed that the incidence of dull chest pain is higher in malignant disease, while pleuritic chest pain is higher in patients with benign disease. Symptoms of less than seven days occur mostly in benign diseases. Marel et al., ${ }^{[7]}$ also reported similar findings.

The most frequent cause of exudative effusion was tuberculosis $(55 \%)$ followed by pneumonia (10\%), malignancy $(8.33 \%)$ and empyema $(6.66 \%)$. The remaining cases were due to trauma, liver disease, hepatic abscess, pelvic abscess, myocardial infarction, and pancreatitis. Hence our study is in accordance with the study done by Alusi. $^{[8]}$

Transudative effusions are usually characterised by a majority of lymphocytes or other mononuclear cells. In our study also $83.33 \%$ samples of transudative effusion had more than $50 \%$ lymphocytes.

When exudative effusions are considered, all but one $(96.86 \%)$ of tuberculous effusions had more than $50 \%$ small lymphocytes. This pattern of lymphocyte predominance was observed in malignant (44\%) Thus our study correlates with the study done by Light and Erozan. The pattern of predominantly polymorphonuclear cells was seen in most effusions secondary to pneumonia, post myocardial infarction, empyema, hepatic abscess, and pelvic abscess.

Our study is in accordance with the study done by Epstein et al. ${ }^{[9]}$ and showed that the majority of tuberculous effusions had more than 50\% lymphocytes, $81.25 \%$ had greater than $5 \mathrm{gm} / \mathrm{dl}$ of protein and $90.63 \%$ had glucose greater than 50 gm/dl. Aggarwal et al., ${ }^{[10]}$ showed that tuberculous effusions rarely contain more than 5\% mesothelial cells which is in agreement with our study.

The presence of predominantly polymorphonuclear cells in pleural fluid indicates that the fluid is the result of acute pleural inflammation, hence raising the probability of pneumonia with effusion. In the present study we got a case of a 55-year-old male patient with a history of trauma, where $15 \%$ eosinophils were found in the pleural fluid. So a diagnosis of eosinophilic pleural effusion was made. Fluid was hemorrhagic in nature. This can be attributed to the fact that the blood in the pleural space acts as an eosinotactic substance. Undoubtedly, there are other factors involved since a significant number of eosinophilic effusions are non-hemorrhagic and not all hemorrhagic effusions are eosinophilic. ${ }^{[10]}$ Air in pleural space has been shown to be another cause of eosinophilic inflammatory response.

It is possible to diagnose the type and source of malignant tumor cells in serous effusions with an overall accuracy of $50 \%$. In the present study, 5 samples with malignancy, the primary site could be confirmed on cytology in $5(100 \%)$ of cases In the present study mesothelioma was the second most common malignancy accounting for two samples (6.06\%). Mesothelial cells were arranged singly or in three dimensional groups. These cell clusters had spherical morule like configuration. Single atypical mesothelial cells were also present. Atypical nuclear features, such as variation in nuclear size, shape, multinucleation, hyperchromasia and enlarged nucleoli were seen. The cells had dense perinuclear cytoplasm, centrally placed nuclei and slit like spaces between some cells. There was also focal vacuolisation of the cytoplasm and a prominent lymphocytic infiltrate. Grandos et al., ${ }^{[11]}$ showed similar findings in cytologic analysis of fluid from malignant mesothelioma. 


\section{Conclusion}

The present study demonstrates that the most useful testin establishing the diagnosis of pleural effusion is pleural fluid cytology and pleural fluid cell count. Cytologic study of pleural fluid is a complete diagnostic modality which aims at pointing out the etiology of effusion as well as, in certain cases, a means of prognostication of disease process. The diagnostic performance may be attributable to the fact that the cell population present in the sediment is representative of a much larger surface area than that obtained by needle biopsy. Detailed study of cytomorphologic features of various metastatic malignant cells in pleural effusions provide definite clues regarding the primary site. Thus patients with an undiagnosed pleural effusion should be evaluated in an individualised stepwise manner. The initial two steps should be relatively non-invasive and should include clinical evaluation and cytologic study.

\section{Financial support and sponsorship- Nil}

Conflicts of interest- There are no conflicts of interest.

\section{References}

1. Cheson BD. Clinical utility of body $\mathrm{fl}$ uidanalysis.Clin Lab Med 1985;5:195-208.

2. Pandit S, Chaudhuri AD, Datta SB, Dey A, Bhanja P. Role of pleural biotpsy in etiological diagnosis of pleural effusion. Lung India. 2010;27:202-4.

3. Gaur DS, Chauhan N, Kusum A, Harsh M, Talekar M, Kishore S, et al. Pleural fluid analysis - Role in diagnosing pleural malignancy. J Cytol. 2007;24:183-8.

4. Frist B, Kahan AV, Koss LG. Comparison of the diagnostic values of biopsies of the pleura and cytologic evaluation of pleural fl uids. Am J ClinPathol 1979;72:48-51.

5. Sherwani R, Akhtar K, Naqvi AH, Akhtar S, Abrari A, Bhargava R. Diagnostic and prognostic significance of cytology in effusions. J Cytol 2005;22:73-7.
6. Frist B, Kahan AV, Koss LG. Comparison of the diagnostic values of biopsies of the pleura and cytologic evaluation of pleural fl uids. Am J ClinPathol 1979;72:48-51.

7. Marel M, Stastny B, Melinova L, Svandova E, Right RW. Diagnosis of pleural effusions: Experience with clinical studies, 1986-1990. Chest 1995;107:1598603.

8. Alusi FA. Pleural effusion in Iraq: A prospective study of 100 cases. Thorax 1986;41:492-3.

9. Epstein DM, Kline LR, Albelda SM, Miller WT. Tuberculous pleural effusions. Chest 1987;91:106-9.

10. Aggrawal AN, Gupta D, Jindal SK. Diagnosis of tuberculous pleural effusion. Indian J Chest Dis Allied Sci 1999;41:89100.

11. Granados R, Libas ES, Fletcher JA. Cytogenetic analysis of effusions from malignant mesothelioma. ActaCytol 1994;38:711-7.

12. Pandit S, Chaudhuri AD, Datta SB, Dey A, Bhanja P. Role of pleural biotpsy in etiological diagnosis of pleural effusion. Lung India. 2010;27:202-4.

13. Maldhure BR, Bedarkar SP, Kulkarnl HR, Paplnwar SP. Pleural biopsy and adenosine deaminase in pleural fluid for the diagnosis of tubercular pleural effusion. Ind J Tub. 1994;41:161-5. 